\title{
Effects of Mixture Toxicity of Erythromycin, Diclofenac and Ibuprofen on the Freshwater Isopod, Asellus aquaticus
}

\author{
Ogunbanwo Olatayo Michael ${ }^{1,2}$ \\ ${ }^{1}$ Department of Fisheries Technology, Aquatic Ecotoxicology Research Laboratory, School of Agriculture, Lagos State Polytechnic, Ikorodu, \\ Lagos State, Southwest Nigeria \\ ${ }^{2}$ Faculty of Environment, School of Geography (Physical), University of Leeds, Leeds, UK
}

\section{Email address:}

tayogunbanwo@yahoo.com,ogunbanwo.o@mylaspotech.edu.ng

\section{To cite this article:}

Ogunbanwo Olatayo Michael. Effects of Mixture Toxicity of Erythromycin, Diclofenac and Ibuprofen on the Freshwater Isopod, Asellus aquaticus. International Journal of Ecotoxicology and Ecobiology. Advances in Materials. Vol. 6, No. 3, 2021, pp. 41-49.

doi: $10.11648 /$ j.ijee.20210603.11

Received: April 13, 2021; Accepted: July 10, 2021; Published: July 16, 2021

\begin{abstract}
Pharmaceuticals are continuously released into the aquatic environment mostly as wastewater effluents through sewage treatment plants, run-offs, effluents from pharmaceutical manufacturing companies etc. This results in chronic exposure of aquatic organisms to these substances and their metabolites. Although, the concentrations of pharmaceuticals in the aquatic environment are usually in $\mathrm{ngL}^{-1}$ to $\mu \mathrm{g} \mathrm{\textrm {L } ^ { - 1 }}$ range, they are not likely to result in lethal toxicity. Nevertheless, extended and unabated exposure to low concentrations of drugs could lead to sublethal effects or even multigenerational effects. The aim of this study was to seek to improve the understanding of the effects of prolonged low-level exposure of Asellus aquaticus (aquatic macro-invertebrates) to mixtures of erythromycin, diclofenac and ibuprofen. On exposure to the mixture, growth rate decreased, feed intake was reduced but mortality was not significant for A. aquaticus. The effects of these pharmaceuticals on the growth, feeding and mortality of the test animal were as a result of the actions of the drugs and not attributed to a more general stress response. Although pharmaceuticals are indispensable to human health their usage and discharge to the aquatic environment coupled with their ecotoxicity to aquatic life may lead to ecological problems in the near future. Furthermore, this research confirms the suitability of the test species (A. aquaticus) as ecotoxicological test species that is both amenable to laboratory culture and sufficiently sensitive to provide reliable quantification of environmental risk.
\end{abstract}

Keywords: Pharmaceuticals, Sub-lethal, Asellus Aquaticus, Mixture Toxicity, Ecotoxicology

\section{Introduction}

Pharmaceuticals are consumed all over the world including the poorest countries on the planet because it increases life span, sustainability of lives, increases human productivity and mass production of food and livestock to sustain evergrowing human population [36]. As a result, in the last few decades, global manufacturing of pharmaceuticals had increased geometrically $[5,36]$. However, the presence of these drugs in the aquatic environment may elicit unintended biological response on non-target organisms among other responses, physiological changes, such as feeding, growth, mobility and behavioural changes are most vulnerable/important endpoints for assessing the effects of pharmaceuticals on aquatic organisms [38, 27, 49, 7].

Over the years, invertebrates have been found useful as model animals for investigating the toxicity of compounds in the environmental [13, 43, 51, 21, 35]. Macro invertebrates has been used regularly in the past for measuring the toxicity of chemicals because they are sensitive to toxic compounds and environmentally significant $[26,37]$. They are simple to handle, easy to rear, varieties of animal species to choose from and have short life span, hence, they are suitable for toxicity testing of water [35].

The test animal-Asellus aquaticus, a freshwater isopod, was chosen because they play a significant part in freshwater environment; they are leaf shredders and transfer and store metabolic energy within the ecosystems [54, 22]. They also serve as food for both fish and invertebrate predators $[50,32,14,10]$. Asellus aquaticus has a life cycle of one year and has been used as a test species in toxicity testing experiments both in the laboratory and the field [50, 
33, 3, 19]. They serve as an indicator of the health of stream, can be found in large number and breed in captivity and very slow in movement in water. Unlike G. pulex that is a water column dweller $A$. aquaticus are sediment-dwellers and constantly in contact with contaminants both in the water column and sediments [32]. They are seen as a robust organism, tolerant to fluctuations of $\mathrm{pH}$ value, dissolved oxygen concentrations and other physico-chemical parameters [21]. They are considered to be relatively tolerant to pollution $[1,31,4,3]$, but can be sensitive to trace metals [33]. They play a prominent role in transfer of contaminants in the aquatic food chain [41, 30,38]. Their small size and robust nature make them ideally suited for application in toxicity tests and eliminating them will disrupt the balance in the ecosystem $[9,50]$. Hence, they are of great importance for the sustainability and balancing in the ecosystem. Very few studies have investigated effects of pharmaceuticals on A. aquaticus in the aquatic environment; in the past three decades the majority of work done using this model organism focused on metal pollution. For example, mercury, cadmium and copper were found by Ort, C. and Siegrist, $\mathrm{H}$. to be toxic to A. aquaticus [39]. Long-term effects of metals on $A$. aquaticus mortality were investigated by Van Ginneken et al and found that lethal concentrations were lower than nominal and effective concentrations [53]. Plahuta et al investigated the effects of exposure of $A$. aquaticus to selected organic pollutants and found that there were significant effects on the mortality rate [43]. In a similar experiment by De Nicola Giudici et al., the effects of chronic exposure to $5 \mu \mathrm{gL}^{-1}$ cadmium and copper on A. aquaticus were investigated and it was found that the juvenile body growth was stimulated by cadmium and depressed by copper [17]. Other studies in which $A$. aquaticus were exposed to metal toxicity were [33, 48, 44, $23,24,42,14,10]$.

The current work investigated the use of $A$. aquaticus (bottom/sediment dweller) as an indicator to evaluate the potential effects of contaminants and the ecological effects of prolong low-level exposure of $A$. aquaticus to mixtures of erythromycin, diclofenac, ibuprofen at environmentally relevant concentrations on growth, feeding and mortality with the aim of broadening knowledge about the potential risk of such contaminants to aquatic ecosystems.

\section{Materials and Methods}

\subsection{Study Compounds}

The study compounds (erythromycin, diclofenac and ibuprofen) were chosen based on their high prescription rates, volumes and availability of a reliable analytical method. They are among the 25 most prescribed drugs in the United Kingdom (UK) and because of their widespread occurrence in rivers worldwide [25]. Calculations of the ratio of predicted environmental concentration (PEC) and predicted no effect concentration (PNEC) has shown that the ratios for these drugs exceeded one. A risk quotient $(\mathrm{RQ}) \geq 1$ indicates the potential for impacts on aquatic organisms [28]. Hence, the basis for their selection. (Table 1).

Table 1. Physico-chemical properties of the study compounds.

\begin{tabular}{|c|c|c|c|c|c|}
\hline Compound & CAS number & $\begin{array}{l}\text { Purity } \\
(\%)\end{array}$ & $\begin{array}{l}\text { Molecular } \\
\text { weight }(g / m o l)\end{array}$ & $\begin{array}{l}\text { Molecular } \\
\text { formula }\end{array}$ & Physico-chemical properties and risk quotients \\
\hline Erythromycin & 114-07-08 & $>99$ & 733.93 & $\mathrm{C}_{37} \mathrm{H}_{67} \mathrm{NO}_{13}$ & $\begin{array}{l}\text { Solubility }\left(\mathrm{mgL}^{-1}\right)=1.44, \mathrm{pKa}=8.9, \log \mathrm{Kow}=2.48, \text { Excretion rate }=5 \% \\
\text { parent, } \mathrm{RQmin}=0.01, \mathrm{RQmax}=1.25\end{array}$ \\
\hline Diclofenac & $15307-79-6$ & $>98$ & 296.148 & $\mathrm{C}_{14} \mathrm{H}_{10} \mathrm{Cl}_{2} \mathrm{NNaO}_{2}$ & $\begin{array}{l}\text { Solubility }\left(\mathrm{mgL}^{-1}\right)=2430, \mathrm{pKa}=4.0, \log \text { Kow }=4.02, \text { Excretion rate }=15 \% \\
\text { parent, }<1 \% \text { conjugate, } \mathrm{RQmin}=0.01, \mathrm{RQmax}=1.13\end{array}$ \\
\hline Ibuprofen & $15687-27-1$ & 98 & 206.29 & $\mathrm{C}_{13} \mathrm{H}_{18} \mathrm{O}_{2}$ & $\begin{array}{l}\text { Solubility }\left(\mathrm{mgL}^{-1}\right)=21.00, \mathrm{pKa}=4.91, \log \mathrm{Kow}=3.79, \text { Excretion rate }=1 \% \\
\text { parent, } \mathrm{RQmin}=0.55, \mathrm{RQmax}=4.20\end{array}$ \\
\hline
\end{tabular}

$\mathrm{pKa}=$ dissociation constant; $\log$ Kow $=$ octanol: water partition coefficient; RQ data from: [28, 47, 52, 35].

\subsection{Materials}

Erythromycin, diclofenac and ibuprofen (Table $1 \&$ Figure 1) were purchased from Sigma-Aldrich, (Dorset, UK). High performance liquid chromatography (HPLC) grade methanol was purchased from Fischer Scientific (Loughborough, UK). Ultra-pure water was obtained from a Sartorius Purite Select HP160/BP/IT water purification system with a specific resistance of $18.2 \mathrm{M} \Omega \mathrm{cm}$. Chemical stock solutions for each compound were prepared in methanol on a weight basis in $100 \mathrm{ml}$ of $100 \%$ methanol and stored at $-20^{\circ} \mathrm{C}$, and the working solutions were diluted aliquots of the stock solutions $\left(100 \mathrm{mgL}^{-1}=10 \mathrm{mg} / 100 \mathrm{ml}\right)$. Glassware and vessels were disinfected then pre-rinsed with $100 \%$ methanol and ultrapure water twice and left to dry in the fume cupboard prior to the experiments.

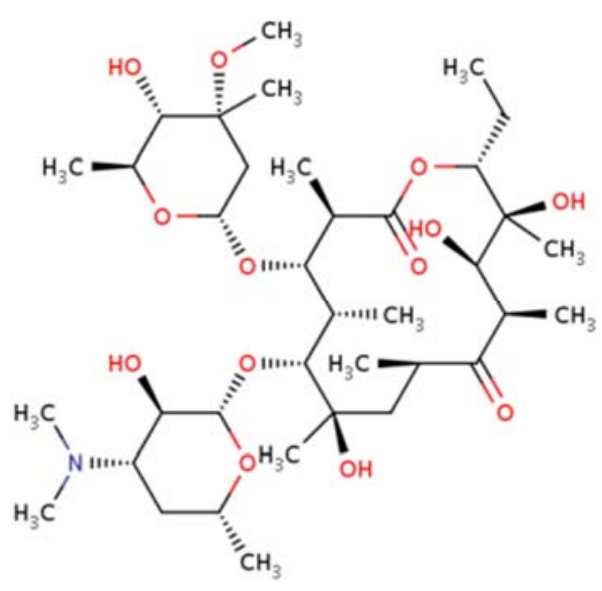

A 
<smiles>COC(=O)Cc1ccccc1Nc1c(Cl)cccc1Cl</smiles>

B<smiles>CC(C)Cc1ccc(C(C)C(=O)O)cc1</smiles>

$\mathrm{C}$

Figure 1. Chemical structures of erythromycin (A), diclofenac (B) and ibuprofen (C) from left to right respectively. Image from (Sigma-Aldrich).

\subsection{Preparation of Solutions}

Environmentally relevant concentrations of each of the compounds ERY, DIC, IBU were mixed together and used in these experiments (UK mean measured environmental concentration [LT] and UK maximum measured environmental concentration [HT]). These treatment concentrations were chosen as an indicator of likely exposures based on published data for UK rivers $[6,25]$ and an indicator of worst-case exposure scenario based on maximum concentrations in UK rivers.

One hundred $\mathrm{mgL}^{-1}$ solutions $\left(100 \mathrm{mgL}^{-1}=10 \mathrm{mg} / 100 \mathrm{ml}\right)$ of each of the compounds (ERY, DIC and IBU) were prepared by dissolving each separately in methanol (HPLC grade) to make the stock solutions. $1 \mathrm{~mL}$ was measured from each stock solution and each dissolved in $100 \mathrm{~mL}$ of solvent to make the intermediate solution for each compound. For the mixture experiment environmental concentrations of each of the compounds were measured from the intermediate solutions, mixed together and dissolved in $250 \mathrm{~mL}$ of solvent to form the working solution. All solutions were stored at $-20^{\circ} \mathrm{C}$ in the dark for optimum stability and to avoid photodegradation.

The working solutions of LT and HT were poured on transparent silica glass beads and allowed to evaporate to dryness in the fume cupboard in order to avoid methanol toxicity, then the dried extracts were reconstituted/resuspended with $10 \mathrm{~mL}$ of pond water and washed into the beakers before A. aquaticus were introduced.

Before the transparent silica glass beads were reused, they were washed with ultra clean water, ashed in the furnace at $550^{\circ} \mathrm{C}$ and allow to cool in the fume cupboard to prevent toxicity in any form to the test animals. Separate beads were used for the different treatments and controls to prevent contamination.

\subsection{Test Animals: Origin and Maintenance}

Asellus aquaticus (Plate 1) used for the experiments were collected in ponds at Bramham estate, Leeds, West Yorkshire, United Kingdom. This site was chosen because it was located upstream of any STP effluent inputs, hence reducing the possibility for pollution by the compounds being investigated. The test animals were sampled with a net from 1.5 to $4 \mathrm{~m}$ depth. A. aquaticus individuals were hand selected from other organisms and detritus and then brought to the laboratory in cool boxes $\left(5^{\circ} \mathrm{C}\right)$. Isopods of approximately the same size averaging $22.29 \pm 1.31 \mathrm{mg}$ were used for the experiments. Individuals were sexed by placing pre-copular pairs on a dry filter paper and allowing them to disentangle from each other and kept in incubators at $12^{\circ} \mathrm{C}$ with a diurnal light rhythm of $16 \mathrm{~h}: 8 \mathrm{~h}$ (day-night) and allowed to acclimatize in aerated pond water before the exposure experiments started.

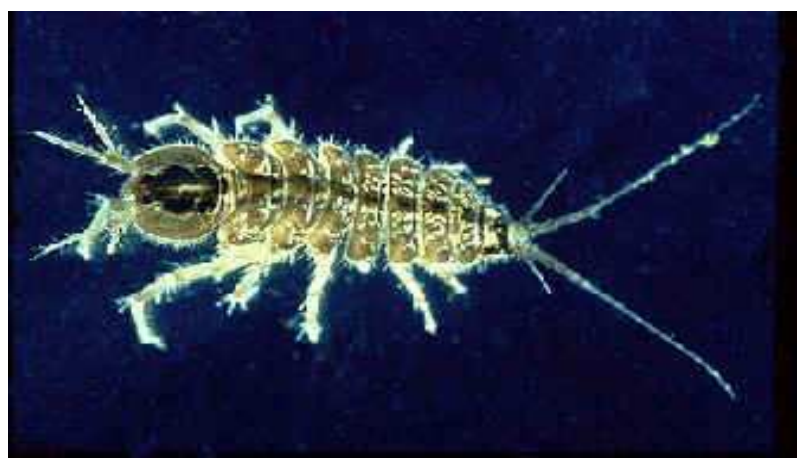

Plate 1. Asellus aquaticus (pollution tolerant) Source: [35].

\subsection{Preparation of Leaf Material for Feeding of Test Animals}

Alnus glutinosa (Alder leaves) were collected from Bramham Estate near the ponds and oven dried at $60^{\circ} \mathrm{C}$ for $24 \mathrm{hrs}$. The leaves were conditioned in a nutrient medium [8] in an aerated bucket at room temperature for 10 days together with alder leaves previously exposed in the ponds in which the test animals were collected. This was to establish a natural microbial community consisting of fungi and bacteria. This conditioning process increases the nutritive value of leaf material for shredders, such as A. aquaticus [2], and simulates the environmentally relevant processes. $A$. aquaticus were fed with $0.1 \mathrm{~g}$ of the conditioned/standardized alder leaves (Alnus glutinosa).

\subsection{Exposure Media}

Water from Bramham Park ponds (where the animals were sourced) was used for this experiment. The physico chemical parameters at the point of collection of the culture media were, dissolved oxygen (DO): $12.3 \mathrm{mgL}^{-1}$, water temperature: $17.2^{\circ} \mathrm{C}$, electrical conductivity (EC): $662 \mu \mathrm{S}$ $\mathrm{cm}^{-1}$ and $\mathrm{pH}:$ 7.5. The $\mathrm{pH}, \mathrm{DO}$, water temperature and EC were measured weekly with a HACH HQ40d multimeter and the instruments were rinsed with deionized water before every reading taken. 


\subsection{Experimental Design}

For the mixture experiments, there were two treatments (LT and HT) and solvent controls (SCTR) with 15 replicates of each treatment and 15 replicates of the control. Test concentrations were selected to mimic environmental detection levels reported for UK rivers in the literature. The low treatments (LT) were UK mean measured environmental concentrations of $159.7 \mathrm{ngL}^{-1}$ (ERY), $202.2 \mathrm{ngL}^{-1}$ (DIC), $420.8 \mathrm{ngL}^{-1}$ (IBU) and the high treatments were $1377.8 \mathrm{ngL}^{-1}$ (ERY), $2990.7 \mathrm{ngL}^{-1}$ (DIC) and $4838.4 \mathrm{ngL}^{-1}$ (IBU) respectively $[25,6]$ and the solvent control contained $0.1 \mathrm{mI}$ $\mathrm{L}^{-1}$ of methanol.

Table 2. Concentrations of the test compounds (environmental detection levels reported for UK). Sources: [25, 6].

\begin{tabular}{lll}
\hline Compound & Low & High \\
\hline & Concentration $\left(\mathbf{n g L}^{-1}\right)$ & Concentration $\left(\mathbf{n g L} \mathbf{L}^{-1}\right)$ \\
\hline Erythromycin & 159.7 & 1377.8 \\
Diclofenac & 202.2 & 2990.7 \\
Ibuprofen & 420.8 & 838.4 \\
\hline
\end{tabular}

For the mixture experiments, the low and high treatments were mixtures of ERY, DIC and IBU concentrations. The experiments were carried out in clear glass SS jar $(500 \mathrm{~mL})$ kept in incubators (figure 2) at a temperature of $12^{\circ} \mathrm{C}$ and 16 : $8 \mathrm{~h}$ light: dark regime. The animals were illuminated with a fluorescent light (with a specification for freshwater invertebrates), to simulate on a small scale the macroinvertebrates' natural climatic condition. The glow mimicked the thermal warmth and daytime illumination obtained from the sun radiation.

Each glass jar contained one A. aquaticus with $300 \mathrm{ml}$ of pond water, which was assigned and arranged randomly in the experimental chambers using a random integer generator. Individuals were weighed individually at the start of the experiment and subsequently every week with a Sartorius Quintex 224-1s balance.

The working solutions of LT and HT were poured on transparent silica glass beads and allowed to evaporate to dryness in the fume cupboard in other to avoid methanol toxicity, then the dried extracts were reconstituted/resuspended with $10 \mathrm{ml}$ of pond water and washed into the beakers before $A$. aquaticus were introduced.

Before the transparent silica glass beads were reused, they were washed with ultra-clean water, ashed in the furnace at $550^{\circ} \mathrm{C}$ and allow to cool in the fume cupboard to prevent toxicity in any form to the test animals.

For the mixture experiments, forty-five (45) A. aquaticus were used, Exposures were static renewal with $100 \%$ water replacement every week with fresh concentrations of the pharmaceuticals and the experiments were run for 4 (four) weeks. Growth was measured weekly by deducting the initial mass of each $A$. aquaticus from the mass each week. Mortality was determined at the end of the experiments by counting the surviving animals and calculating percentage mortality. Remaining alder leaves (feed material) at the end of the experiments were oven dried, weighed and combusted to determine the feeding rate (ash free dry mass).

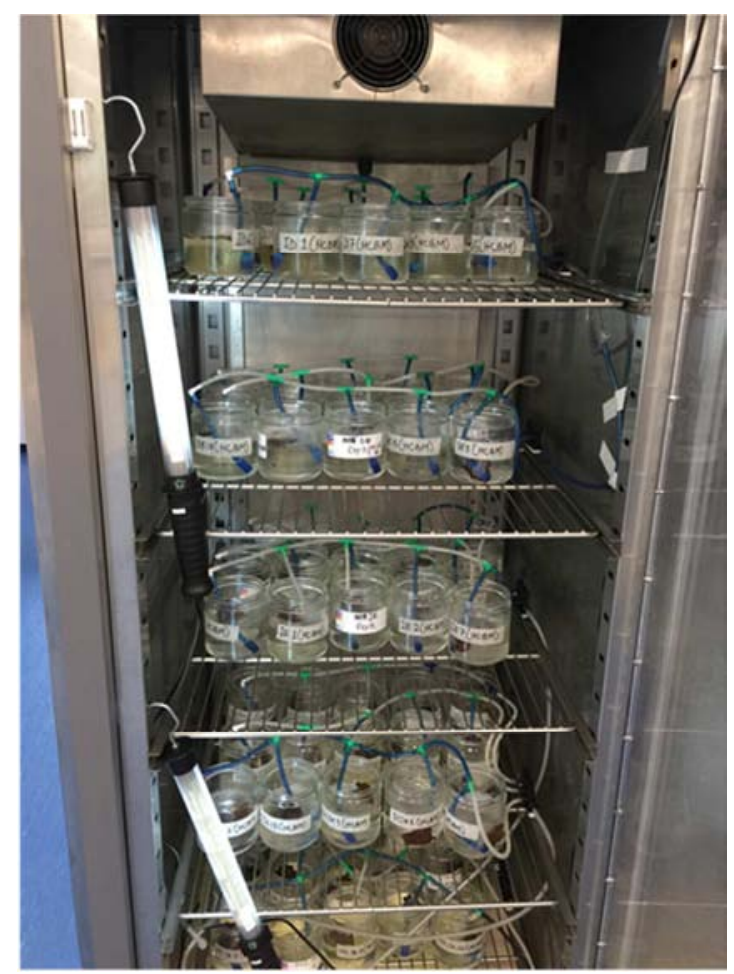

Figure 2. One of the experimental set-ups in the incubators showing the arrangement of the jars with one A. aquaticus in each jar exposed to experimental media (Solvent control (STCR), Low treatment (LT) \& High treatment (HT)).

\section{Data Analysis}

Data were organized using Excel (Microsoft, 2013) and residuals of the data were checked for normal distribution using the Shapiro-Wilk normality test and homogeneity of variance using the Bartlett test of homogeneity of variances. R (R Development Core Team, 2008) was used to analyses the data and create figures (Box-and-Whisker). The box-andwhisker plots display a statistical summary of variables: median, quartiles, range and possibly extreme values (outliers). An outlier value is defined as a value that is smaller than the lower quartile ( 25 percentile) minus 1.5 times the interquartile range, or larger than the upper quartile (75 percentile) plus 1.5 times the interquartile range. Changes in Asellus aquaticus mass, physicochemical parameters and mass of feed materials (Alnus glutinosa) from week 1 to week 4 were tested using generalized linear model and Chisquare. Mortality was analyzed using one-way ANOVA where assumptions of normality and homogeneity were met followed by Tukey's post-hoc tests to identify and compare the treatment means with the respective controls

\section{Results}

\subsection{Initial Test Conditions}

When the experiment was initiated (day 0 ) the average mass of $A$. aquaticus was $22.32 \mathrm{mg} \pm 1.45 \mathrm{SD}$ for control 
(SCTR), $22.19 \mathrm{mg} \pm 1.31 \mathrm{SD}$ for low treatment (MIX-LT) and $22.37 \mathrm{mg} \pm 1.24 \mathrm{SD}$ for high treatment (MIX-HT). There was no statistically significant difference in test organism mass between the treatments and the control (ANOVA: $F_{2}, 42$ $=0.073, \mathrm{p}=0.929)$.

\subsection{Growth}

When the residuals of the data were analysed for change in mass over the course of the experiment, there were statistically significant differences between the treatments and the control (GLM: $\left.\chi^{2}(2)=10.07, \mathrm{p}<0.01\right)$, (Figure 3).

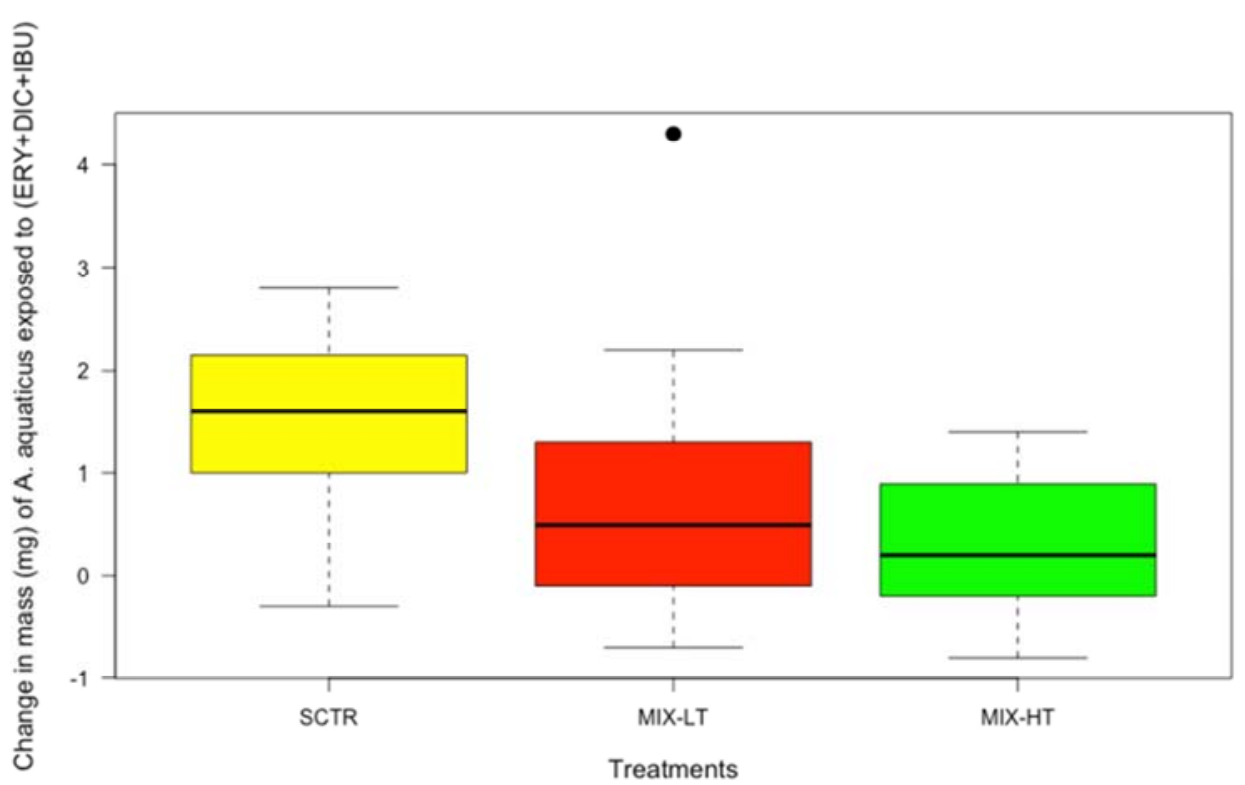

Figure 3. Boxplots displaying change in mass of A. aquaticus exposed to mixtures of erythromycin, diclofenac and ibuprofen after 4 weeks static renewal experiments. Solvent control (SCTR), low treatment (MIX-LT) and high treatment (MIX-HT). The dark horizontal line inside the box represents the median $\left(50^{\text {th }}\right.$ percentile), top of the coloured box represents $3^{\text {rd }}$ quartiles $\left(75^{\text {th }}\right.$ percentile), top whisker represents $4^{\text {th }}$ quartiles $\left(90^{\text {th }}\right.$ percentile), bottom of the coloured box represents the $2^{\text {nd }}$ quartiles $\left(25^{\text {th }}\right.$ percentile) and the vertical lines represents the $1^{\text {st }}$ quartiles $\left(10^{\text {th }}\right.$ percentile). There was outlier.

\subsection{Feeding}

There were statistically significant differences in the mass of feed materials between control and treatments (ANOVA: $\mathrm{F}_{(2,42)}$ $=6.72, \mathrm{p}<0.01)$. The mass loss of Alnus glutinosa litter by the control was higher than those in the treatment groups i. e. feeding rate in the control was higher than the treatments, (Figure 4).

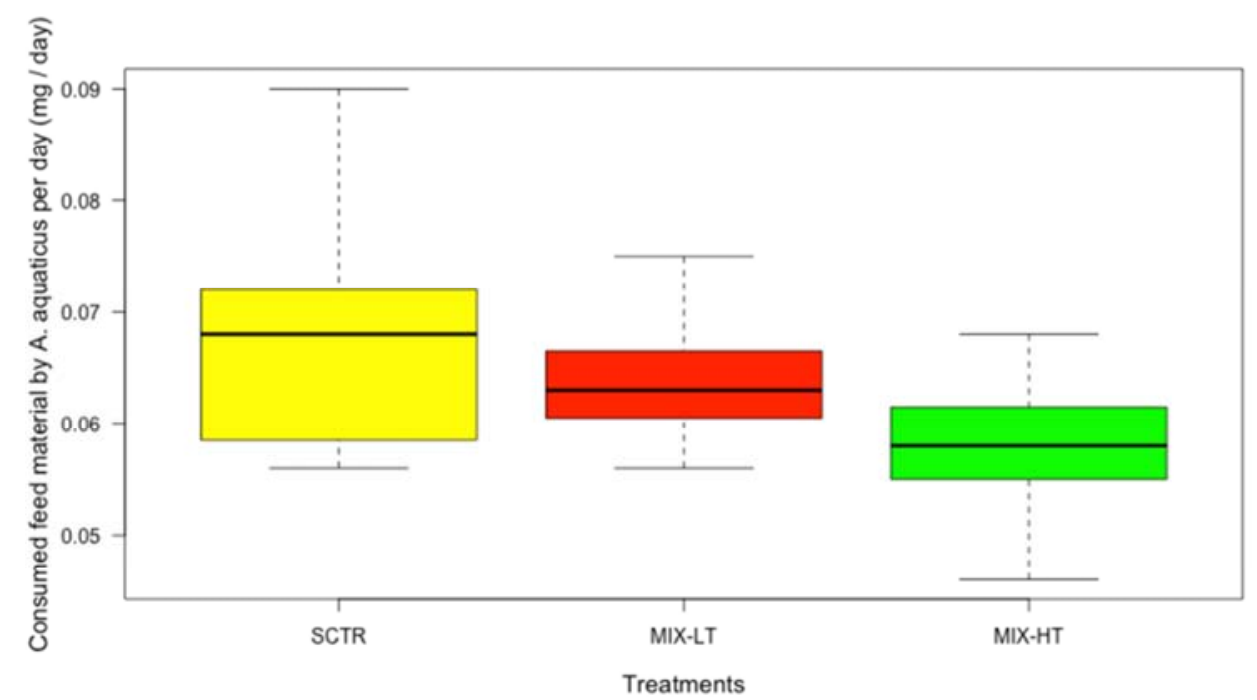

Figure 4. Boxplots displaying consumed feed materials by A. aquaticus exposed to environmental relevant concentrations of mixtures of erythromycin, diclofenac and ibuprofen after 4 weeks static renewal experiments. Solvent control (SCTR), low treatment (MIX-LT) and high treatment (MIX-HT). The dark horizontal line inside the box represents the median $\left(50^{\text {th }}\right.$ percentile), top of the coloured box represents $3^{\text {rd }}$ quartiles $\left(75^{\text {th }}\right.$ percentile), top whisker represents $4^{\text {th }}$ quartiles $\left(90^{\text {th }}\right.$ percentile), bottom of the coloured box represents the $2^{\text {nd }}$ quartiles $\left(25^{\text {th }}\right.$ percentile) and the vertical lines represents the $1^{\text {st }}$ quartiles (1 ${ }^{\text {th }}$ percentile). There were no outliers. 


\subsection{Mortality}

Mortality did not occur in the control throughout the duration of the experiments. One and two mortalities were recorded in the fourth week of the experiments in the MIX-
LT and MIX-HT respectively (Figure 5) but there was no statistically significant difference between the treatments and control $\left(\mathrm{GLM}: \chi^{2}(2)=22.11, \mathrm{p}=0.56\right)$.

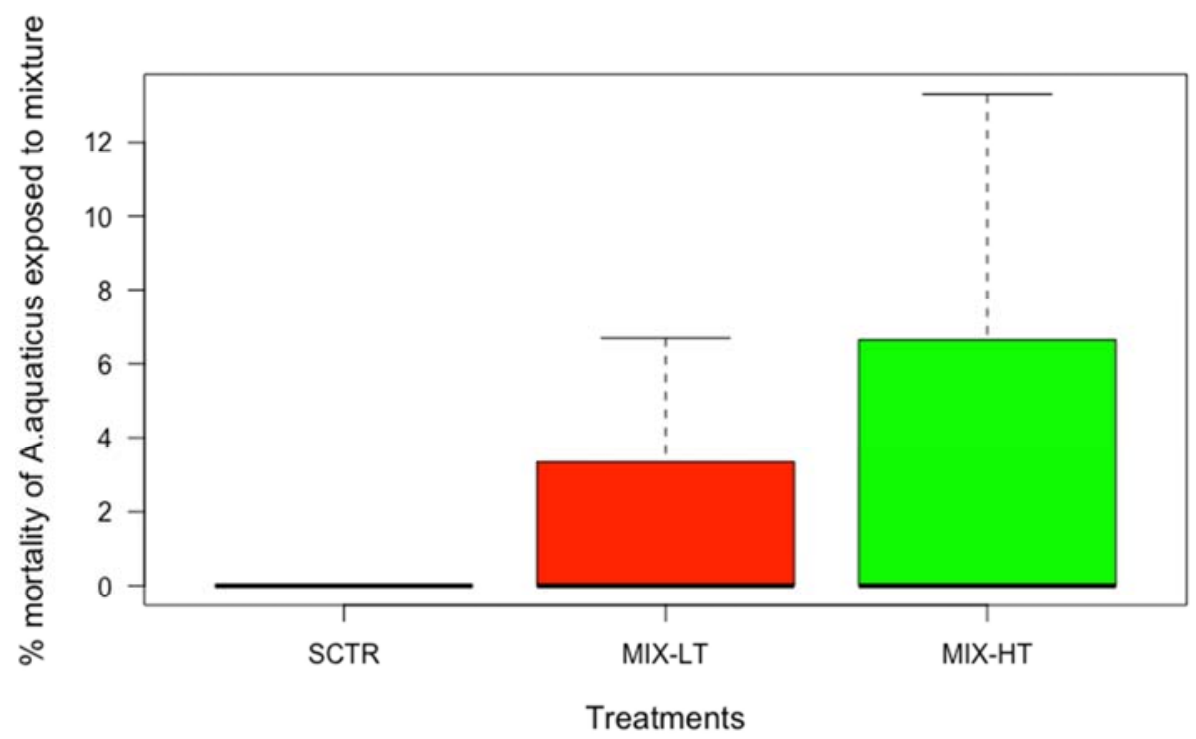

Figure 5. Boxplots displaying\% mortality of A. aquaticus exposed to environmental relevant concentrations of mixtures of erythromycin, diclofenac and ibuprofen after 4 weeks static renewal experiments. Solvent control (SCTR), low treatment (MIX-LT) and high treatment (MIX-HT). The dark horizontal line inside the box represents the median ( $50^{\text {th }}$ percentile), top of the coloured box represents $3^{\text {rd }}$ quartiles $\left(75^{\text {th }}\right.$ percentile), top whisker represents $4^{\text {th }}$ quartiles $\left(90^{\text {th }}\right.$ percentile), bottom of the coloured box represents the $2^{\text {nd }}$ quartiles $\left(25^{\text {th }}\right.$ percentile) and the vertical lines represents the $1^{\text {st }}$ quartiles $\left(10^{\text {th }}\right.$ perc entile). There were no outliers.

\section{Discussion}

The aim of this study was to seek to improve the understanding of the effects of prolonged low-level exposure of Asellus aquaticus to mixtures of erythromycin, diclofenac and ibuprofen. There are few data on the use of $A$. aquaticus as a test species in pharmaceutical effect studies but there is substantial information on its use in metal toxicity. This study is one of the few in which A. aquaticus is used in pharmaceutical effect studies.

Effects of Mixtures of Erythromycin, Diclofenac and Ibuprofen on Growth, Feeding and Mortality on A. aquaticus

Going forward in the present study, effects of mixtures of erythromycin, diclofenac and ibuprofen at relevant environmental concentrations via direct (waterborne) exposure pathway on Asellus aquaticus in a 4-week bioassay was investigated. Sublethal responses such as growth, feeding behaviour and mortality were analyzed. It was observed that the mixture negatively affected the growth and feeding activities of the test organism. However, synergism was exhibited in this present study, this maybe as a result of different receptors targeted by the compounds, NSAIDs targeting COX $1 \& 2$ and ERY targeting prokaryotic cells. In a similar investigation by Quinn et al in which Hydra was exposed to mixtures of pharmaceuticals for $96 \mathrm{~h}$, there was reduction in the ability of the freshwater Hydra to regenerate [45].
Investigations by Parrott, J. L., and Bennie, D. T. also supported the findings in this study, although, Pimephales. promelas (Fathead minnow) was used to study the effects of mixtures of seven drugs at concentrations of $1 \mu \mathrm{g} \mathrm{L}^{-1}$ for 3 months [40]. The degree of defects observed in the fathead minnow were small. Sun et al investigated binary mixtures of a hormone (17 $\beta$-estradiol) with letrozole at environmentally realistic concentration and detected significant decrease in fertility and fecundity after $21 \mathrm{~d}$ of exposure [52].

In a similar study to this experiment, even though different compounds and test species, Dietrich et al exposed Lemna gibba (Fat Duckweed) to different mixture of drugs similar sensitivity was demonstrated by the test species at concentrations 1-300 $\mu \mathrm{g} \mathrm{\textrm {L } ^ { - 1 }}$. After $7 \mathrm{~d}$, the test specie showed sign of necrosis [18].

In a multigenerational mixture experiment in which acetaminophen, diclofenac, ibuprofen and a host of other compounds were used, it was observed that the sex ratio was altered by $17 \%$ more males. In a binary combination (diclofenac and ibuprofen) and quaternary (ibuprofen, acetylsalicylic, naproxen and diclofenac) exposed to D. magna, a very strong additive effect was observed at concentrations of $34-54 \mathrm{mgL}^{-1}$ [11]. Very strong additive effects were also observed when $D$. magna was exposed at concentrations 10 -fold lower than the quaternary concentrations. The body size and reproduction were affected [12].

In a study carried out by Nieto et al, Carcinus maenas was shown to have significant changes in haemolymph osmolality 
and osmoregulatory capacity after being exposed to relevant environmental concentrations of the mixtures $\left(10 \mathrm{ngL}^{-1}\right.$ and 17.5 psu of salinity) [34]. The osmoregulatory ability of the mixture was improved, implying a reduction in benefit by organisms and a rise in haemolymph osmolality [20]. The $A$. aquaticus exposed to the mixtures of erythromycin, diclofenac and ibuprofen started losing weight as a result of the exposure while the control animals are gaining weight weekly. Feeding rate was equally affected, the exposed isopod was feeding at reduced rate in the low and high treatments compared to the control. Hence there was alteration in feeding rate of $A$. aquaticus exposed to the mixture. Similar investigation on Hydra attenuata, showed that minimum concentrations of $10 \mathrm{mgL}^{-1}$ and $50 \mathrm{mgL}^{-1}$ was needed to observe a significant reduction in feeding activities when exposed for $96 \mathrm{~h}$ to ibuprofen and carbamazepine respectively [46]. This concentration was 1000 times higher than the concentrations employed in this study though, with different study compounds and test animals and duration.

De Lange et al established the effects of pharmaceuticals on feeding activities and behaviour of other macroinvertebrate animals, using concentrations similar to those used in this study but different pharmaceutical compounds were used $[15,16]$.

Considering the feeding rate and growth between the control and treatments, one-way ANOVA/GLM results suggested that there was a significant interaction.

The realistic environmental concentrations of isolated compounds such as diclofenac and erythromycin do cause increase mortality, reduced feeding rate and growth. However, when they are in mixtures, these compounds may present increased (synergistic) or reduced (antagonistic) inherent toxicity. Aside this, diclofenac and ibuprofen have similar mode of action (MoA) and hence they may act (additively) synergistically. Addition of erythromycin to this mixture may cause it to act antagonistically, hence the result obtained in this study.

The low and high treatments did not show any sign of increase mortality as a result of the exposure to the mixture. There were only three mortalities throughout the duration of the study, one in the low and two in high treatments and none in the control.

Generally, many scientists agree that concentration addition (CA) is appropriate for estimating mixture toxicity of substances acting in a similar manner, while independent action (IA) assumes that in a mixture of different chemicals, the effects exerted by individual chemical are not dependent on others. The key limitation of the concentration addition model, as Kortenkamp noted, is that differences may be detected for some mixtures containing drugs for which only low effects are detected [29].

\section{Conclusion}

Based on this study, it can be suggested that $A$. aquaticus can be recognized as a reference model test animal and good indicator to evaluate the potential effects of contaminants.
The results of this study showed that the toxicity of drug mixtures is unpredictable, and complex compared to effects of single pharmaceuticals. However, the mixtures showed concentration addition (CA) effects and one of the weaknesses of this model is that differences are sometimes seen for some mixtures containing drugs for which only little effects are detected.

\section{References}

[1] Backhaus, T. \& Karlsson, M. (2011). Screening level mixture risk assessment of pharmaceuticals in STP effluents, Water Research, 49, 157-165.

[2] Bärlocher, F. \& Kendrick, B. (1985). Dynamics of the fungal population on leaves in a stream. Journal of Ecology, 62 (3), 761-791.

[3] Bloor M. C., \& Banks C. J. (2010). An evaluation of mixed species in-situ and ex-situ feeding assays: The altered response of Asellus aquaticus and Gammarus pulex. Environment International, 32, 22-27.

[4] Bloor, M. C., Banks, C. J., \& Krivtsov, V. (2005). Acute and sublethal toxicity tests to monitor the impact of leachate on an aquatic environment. Environment international, 31 (2), 269273.

[5] Borgmann, U., Bennie, D. T., Ball, A. L., \& Palabrica, V. (2007). Effect of a mixture of seven pharmaceuticals on Hyalella azteca over multiple generations. Chemosphere, 66 (7), 1278- 1283.

[6] Bound, J. P. and Voulvoulis, N. (2006). Predicted and measured concentrations for selected pharmaceuticals in UK rivers: Implications for risk assessment. Water Research, 40 (15), 2885-2892.

[7] Boyd, G. R., Reemtsma, H., Grimm, D. A., \& Mitra, S. (2003). Pharmaceuticals and personal care products (PPCPs) in surface and treated waters of Louisiana, USA and Ontario, Canada. The Science of the Total Environment, 311, 135-149.

[8] Brown, K. D., Kulis, J., Thomson, B., Chapman, T. H., Mawhinney, D. B., (2006). Occurrence of antibiotics in hospital, residential, dairy effluent and municipal wastewater in Rio Grande in New Mexico. Science of The Total Environment. 366, 772-783.

[9] Bundschuh, M., Appeltauer, A., Dabrunz, A., Schulz, R. (2012). Combined effect of invertebrate predation and sublethal pesticide exposure on the behavior and survival of Asellus aquaticus (Crustacea; Isopoda). Arch Environmental Contamination Toxicology, 63, 77-85.

[10] Bundschuh, M., Zubrod J. P., Schulz, R., (2012). The functional and physiological status of Gammarus fossarum (Crustacea; Amphipoda) exposed to secondary treated wastewater. Environmental Pollution, 159, 244-249.

[11] Cleuvers, M. (2004). Mixture toxicity of the antiinflammatory drugs diclofenac, ibuprofen, naproxen, and acetylsalicylic acid, Ecotoxicology and Environmental Safety, 59 (3), 309-315.

[12] Cleuvers, M. (2005). Initial risk assessment for three [beta]blockers found in the aquatic environment. Chemosphere, 59 (2), 199-205. 
[13] Daughton, C. G. and Ruhoy, I. S. (2009b). Environmental footprint of pharmaceuticals: The significance of factors beyond direct excretion to sewers. Environmental Toxicology and Chemistry, 28 (12), 2495-2521.

[14] De Jonge M, Blust R, Bervoets L. (2010). The relation between acid volatile sulfides (AVS) and metal accumulation in aquatic invertebrates: Implications of feeding behavior and ecology. Environmental Pollution, 158, 1381-1391.

[15] De Lange, H. J., Noordoven, W., Murk, A. J., Lurling, M., \& Peeters, E. T. (2006). Behavioural responses of Gammarus pulex (Crustacea, Amphipoda) to low concentrations of pharmaceuticals. Aquatic Toxicology, 78, 209-216. European Medicines Evaluation Agency (EMEA).

[16] De Lange, H. J., Peeters, E. T. H. M. and Lürling, M. (2009), Changes in Ventilation and Locomotion of Gammarus pulex (Crustacea, Amphipoda) in Response to Low Concentrations of Pharmaceuticals. Human and Ecological Risk Assessment, $15(1), 111-120$

[17] De Nicola Giudici, M, Migliore, L, Gambardella, C, Marotta, A. (1988). Effect of chronic exposure to cadmium and copper on Asellus aquaticus (L.) (Crustacea, Isopoda). Hydrobiologia, 157: 265-269.

[18] Dietrich, S., Dammel, S., Ploessl, F., Bracher, F., \& Laforsch, C. (2010a). Effects of a pharmaceutical mixture at environmentally relevant concentrations on the amphipod Gammarus fossarum. Marine and Freshwater Research, 61 (2), 196-203.

[19] Ebele, A. J., Abdallah, M. A., Harrad, S, (2017) Pharmaceuticals and personal care products (PPCPs) in freshwater aquatic environment. Emerging contaminants, 3, (1-16).

[20] Furuhagen, S., Liewenborg, B., Breitholtz, M., \& Gorokhova, E. (2014). Feeding activity and xenobiotics modulate oxidative status in Daphnia magna: implications for ecotoxicological testing. Environmental science \& technology, 48 (21), 12886-12892.

[21] Gasperi, J., Sebastian, C., Ruban, V., Delamain, M., Percot, S., Wiest, L., \& Saad, M. (2014). Micropollutants in urban stormwater: occurrence, concentrations, and atmospheric contributions for a wide range of contaminants in three French catchments. Environmental Science and Pollution Research, $21(8), 5267-5281$.

[22] Graca M. A. S., Maltby L., Calow P. (1993). Importance of fungi in the diet of Gammarus pulex and Asellus aquaticus feeding strategies. Oecologia, 93, 139-144.

[23] Grosell M, Gerdes R. M, Brix K. V. (2006). Chronic toxicity of lead to three freshwater invertebrates-Brachionus calyciflorus, Chironomus tentans, and Lymnaea stagnalis. Environmental Toxicology and Chemistry, 25, 97-104.

[24] Grosell M, Nielsen C, Bianchini A. (2002). Sodium turnover rate determines sensitivity to acute copper and silver exposure in freshwater animals. Comp Biochem Physiol C Toxicol Pharmacol 133: 287-303.

[25] Hughes, S. R., Kay, P. \& Brown, L. E. (2013). Global synthesis and critical evaluation of pharmaceutical data sets collected from river systems, Environmental Science and Technology, 47 (2), 661-677.

[26] Hutchinson, T. and Pickford, H. (2002). Reproductive and developmental effects of endocrine disrupters in invertebrates: in vitro and in vivo approaches. Toxicology Letters, 131, 75-81.

[27] Jobling, S. \& Sumpter, J. P. (1993). Detergent components in sewage effluent are weakly oestrogenic to fish: An in vitro study using rainbow trout (Oncorhynchus mykiss) hepatocytes. Aquatic Toxicology, 27 (3-4), 361-372.

[28] Jones, O. A. H., Voulvoulis, N., \& Lester, J. N. (2002). Aquatic environmental assessment of the top 25 English prescription pharmaceuticals. Water Research, 36 (20), 50135022.

[29] Kortenkamp, A., Backhaus, T., and Faust, M. (2009). State of the art report on mixture toxicity- Final report. Study contract no. 070307/2007/485103/ETU/D.1. The school of pharmacy, University of London. Accessed on July 15, 2018. http://ec.europa.eu/environment/chemicals/pdf/report_Mixture $\% 20$ toxicity.pdf.

[30] MacNeil, C., Fielding, N. J., Hume, K. D., Dick, J. T. A., Elwood, R. W., Hatcher, M. J., (2002). Parasite altered microdistribution of Gammarus pulex (Crustacea: Amphipoda). International Journal for Parasitology, 33 (1), 57-64.

[31] Maltby L., Crane M. (1995). Responses of Gammarus pulex (Amphipoda, Crustacea) to metalliferous effluents Identification of toxic comonents and the importance of interpopulation variation. Environmental Pollution, 84, 45-52.

[32] McCahon C. P., Maund S. J., Poulton M. J. (1990). The effect of the acanthocephalan parasite (Pomphorhynchus laevis) on the drift of its intermediate host (Gammarus pulex). Freshwater Biology, 25, 507-513.

[33] Migliore L, \& De Nicola Giudici M. (1990). Toxicity of heavy metals to Asellus aquaticus (L.) (Crustacea, Isopoda). Hydrobiologia, 203, 155-164.

[34] Nieto, E., Hampel, M., Gonzalez-Ortegon, E., Drake, P., and Blasco, J. (2016). Influence of temperature on toxicity of single pharmaceuticals and mixtures, in the crustacean $A$. desmarestii. Hazardous Materials, 313, 159-169.

[35] Ogunbanwo, O. M. (2018). Response of Gammarus pulex to low concentrations of erythromycin. Nigerian Journal of Fisheries, vol. 15, no. 1, pg. 1370-1376.

[36] Ogunbanwo, O. M. (2021). Seasonal variations in the occurrence and distribution of pharmaceuticals in the Odo-Iya Alaro river, Lagos State, Southwest Nigeria. International Journal of Advance Research and Review, 6 (2), pg. 39-67.

[37] Okuda, T., Katsuno, M., Naoi, D., Nakao, S., Tanaka, S., He, K., \& Jia, Y. (2008). Trends in hazardous trace metal concentrations in aerosols collected in Beijing, China from 2001 to 2006. Chemosphere, 72 (6), 917-924.

[38] Orn, S., Holbech, H., and Norrgren, L. (2016). Sexual disrupting in zebrafish (Danio rerio) exposed to mixtures of 17a- ethinylestradiol and 17b-trenbolone. Environmental Toxicology and Pharmacology, 41, 225-231.

[39] Ort, C. and Siegrist, H. (2009). Assessing wastewater dilution in small rivers with high resolution conductivity probes. Water Science and Technology, 59 (8), 1593-1601.

[40] Parrott, J. L., \& Bennie, D. T., (2009). Life-cycle exposure of fathead minnows to a mixture of six common pharmaceuticals and triclosan. Journal of Toxicology and Environmental Health, 72, 633-641. 
[41] Peeters F., Li J., Straile D., Rothhaupt K. O., Vijverberg J. (2000). Influence of low and decreasing food levels on Daphnia-algal interactions: Numerical experiments with a new dynamic energy budget model. Ecological Modelling, 221, 2642-2655.

[42] Pestana, J. L. T., Re A., Nogueira, A. J. A., Soares A. M. V. M. (2007). Effects of cadmium and zinc on the feeding behaviour of two freshwater crustaceans: Atyaephyra desmarestii (Decapoda) and Echinogammarus meridionalis (Amphipoda). Chemosphere, 68, 1556-1562.

[43] Plahuta, M., Tišler, T., Toman, M. J., \& Pintar, A. (2017). Toxic and endocrine disrupting effects of wastewater treatment plant influents and effluents on a freshwater isopod Asellus aquaticus (Isopoda, Crustacea). Chemosphere, 174, 342-353.

[44] Qiu, J. W., Xie, Z. C., Wang, W. X., (2005). Effects of calcium on the uptake and elimination of cadmium and zinc in Asiatic clams. Arch Environmental Contamination and Toxicology, 48, 278-287.

[45] Quinn, B., Gagne, F., \& Blaise, C. (2009). Evaluation of the acute, chronic and teratogenic effects of a mixture of eleven pharmaceuticals on the cnidarian, Hydra attenuata. Science of The Total Environment, 407, 1072-1079.

[46] Quinn, B., Gagné, F. \& Blaise, C. (2008). An investigation into the acute and chronic toxicity of eleven pharmaceuticals (and their solvents) found in wastewater effluent on the cnidarian, Hydra attenuata, Science of The Total Environment, 389 (2-3), 306-314.

[47] Quinn, B., Schmidt, W., O’Rourke, K., \& Hernan, R. (2014). Effects of the pharmaceutical's gemfibrozil and diclofenac on biomarker expression in the zebra mussel (Dreissena polymorpha) and their comparison with standardized toxicity tests. Chemosphere, 84 (5), 657-663.

[48] Rainbow, P. S., \& Black, W. H., (2005). Cadmium, zinc and the uptake of calcium by two crabs, Carcinus maenas and Eriocheir sinensis. Aquatic Toxicology, 72, 45-65.

[49] Rand, G. M., (1985). Fundamentals of aquatic toxicology: Effects, environmental fate, and risk assessment. Chemosphere, 78, 241-248.

[50] Rask, M, \& Hiisivuori, C. (1985). The predation on Asellus aquaticus (L.) by perch, Perca fluviatilis (L.), in a small forest lake. Hydrobiologia, 121, 27-33.

[51] Relic, D., Popovic, A., ĐorCevic, D., Caslavský, J., (2017). Occurrence of synthetic musk compounds in surface, underground, waste and processed water samples in Belgrade, Serbia. Environmental Earth Science, 76 (3), 122.

[52] Sun, M., Arevalo, E., Strynar, M., Lindstrom, A., Richardson, M., Kearns, B., Pickett, A., Smith, C., Knappe, D. R., (2016). Legacy and emerging perfluoroalkyl substances are important drinking water contaminants in the Cape Fear River Watershed of North Carolina. Environmental Science and Technology Letter 3 (12), 415-419.

[53] Van Ginneken, M., Blust, R., Bervoets, L., (2017). How lethal concentration changes over time: toxicity of cadmium, copper, and lead to the freshwater isopod Asellus aquaticus. Environmental Toxicology and Chemistry, 36, 2849-2854.

[54] Van Hecken, A., Schwartz, J. I., Depre, M., De Lepeleire, I., Dallob, A., Tanaka, W. et al. (2000). Comparative inhibitory activity of rofecoxib, meloxicam, diclofenac, ibuprofen, and naproxen on COX-2 versus COX-1 in healthy volunteers. Journal of Clinical Pharmacology, 40 (10), 1109-1120.

[55] Yamamoto, H., Nakamura, Y. Morigushi, S., Nakamura, Y., Honda., Y., Tamura, I., Hirata, Y., Hayashi, A., Sekizawa, J., (2009). Persistence and partitioning of eight selected pharmaceuticals in the aquatic environment: Laboratory photolysis, biodegradation, and sorption experiments. Water Research, 43 (2), 351-362. 